\title{
Physiological features of aggregation of the main formed elements of blood in calves at the beginning of early ontogenesis
}

\author{
Tatyana I. Glagoleva ${ }^{1}$ and Ilya N. Medvedev²,* \\ ${ }^{1}$ All-Russian Research Institute of Animal Physiology, Biochemistry and Nutrition, Branch, Federal Science Center for Animal \\ Husbandry named after Academy Member L.K. Ernst, Borovsk, Institute village, 249013, Russia \\ ${ }^{2}$ Russian State Social University, Moscow, 129226, Russia
}

\begin{abstract}
The need to intensify milk production urgently dictates the need to continue research on the physiology of cattle of any age. It is customary to attach great importance to blood, consisting of uniform elements and plasma, constantly circulating through the vessels. It provides gas exchange, metabolism and the delivery of hormones and bioregulators in their tissues. The success of hemocirculation strongly determines the completeness of the realization of the genetic growth potential and productivity of the animal and is closely related to the activity of aggregation of blood cells. Purpose: to find out the activity of aggregation of the main formed elements of the blood in newborn calves. The work was carried out on 32 newborn calves of black-motley breed, born of healthy cows after 2-3 pregnancies. The calves were examined on 1-2, 3-4, 5-6, 7-8 and 9-10 days of life. In the work, hematological and statistical research methods are applied. For newborns in calves, a tendency towards increased aggregation activity of red blood cells was revealed. This was combined with a low platelet aggregation, which tended to increase. The low aggregation of neutrophils in these calves also gradually increased. In newborn calves of optimal physiological status, there is a tendency to increase the aggregation of the main formed elements of the blood, which is a response to environmental influences.
\end{abstract}

\section{Introduction}

The need for intensification of milk production urgently dictates the need to continue research on the physiology of cattle of any age $[1,2]$. It is customary to attach great importance to blood, consisting of uniform elements and plasma [3], which constantly circulates through the vessels. It provides gas exchange, metabolism and the delivery of hormones and bioregulators in their tissue [4]. The success of hemocirculation strongly determines the completeness of the realization of the genetic growth potential and productivity of an animal $[5,6]$ and is closely related to the activity of aggregation of blood cells [7].

Due to the great social significance of the onset of thrombosis, the aggregation of blood cells [8] has been studied in detail in humans [9]. As a result of these works, mechanisms of aggregation processes important for physiology, their age dynamics, and their disturbances in conditions of pathology were elucidated. It has been established that excessive aggregation of red blood cells, platelets, and white blood cells disrupts metabolic processes and weakens the body [10]. It was possible to establish the possibility of influencing the aggregation processes in the blood. In the presence of cardiovascular pathology, it was possible to show the possibility of obtaining a balance between them due to various effects [11,12].

At present, it becomes clear that the aggregation properties of blood cells strongly determine the rheology of blood and, consequently, the optimum microcirculation in animal tissues during ontogenesis [13]. They are very significant for the growth processes and the maximum development of the productive properties of animals [14].

Moreover, despite the great physiological significance of the aggregation of blood cells for life support processes in all productive animals, such studies have not been conducted in cattle. Their level at the beginning of early ontogenesis, in the neonatal phase, has not yet been evaluated.

To close the gap in physiological knowledge, it was necessary to evaluate the aggregation parameters in newborn calves. These data can enrich physiology and practice, since obtaining knowledge of the norm is necessary for judging the severity of aggregation disorders in newborn calves with any diseases and their dynamics in the case of applying options for correcting the state of animals.

The goal of the work is to find out the activity of aggregation of the main formed elements of blood in newborn calves.

\footnotetext{
* Corresponding author: ilmedv1@yandex.ru
} 


\section{Materials and methods}

The study was conducted in strict accordance with the ethical principles established by the European Convention for the Protection of Vertebrate Animals used for experimental and other scientific purposes (adopted in Strasbourg on March 18, 1986 and confirmed in Strasbourg on June 15, 2006).

The work was carried out on 32 black-motley calves, which were obtained from healthy cows after 2-3 pregnancies. The animals were taken into the study for 1-2 days of life. They were examined five times - on $1-2,3-4,5-6,7-8$ and 9-10 days of life.

In the plasma of calves, thromboxane $\mathrm{B}_{2}$ and 6-ketoprostaglandin $F 1 \alpha$ levels were determined during enzyme-linked immunosorbent assay using kits manufactured by Enzo Life science (USA).

The activity of erythrocyte aggregation was determined using a light microscope in the Goryaev's chamber by the number of red blood cell aggregates, the number of red blood cells aggregated and not entered into aggregation.
The state of platelet aggregation (AP) was evaluated by a visual micromethod using $\operatorname{ADP}\left(0.5 \times 10^{-4} \mathrm{M}\right)$, collagen (1: 2 dilution of the main suspension), thrombin $(0.125 \mathrm{U} / \mathrm{ml})$, ristomycin $(0.8 \mathrm{mg} / \mathrm{ml})$ and adrenaline $\left(5.0 \times 10^{-6} \mathrm{M}\right)$ in plasma, standardized by platelet count to $200 \times 10^{9}$ platelets.

Neutrophil aggregation was evaluated on a photoelectrocolorimeter with inductors: wheat germ lectin $32 \mu \mathrm{g} / \mathrm{ml}$, concanavalin A $32 \mu \mathrm{g} / \mathrm{ml}$ and phytohemagglutinin $32 \mu \mathrm{g} / \mathrm{ml}$.

Statistical processing of the results was carried out by t-student test.

\section{Results}

Initially, the normal number of arachidonic acid metabolites in the blood of calves did not have significant dynamics, being unchanged until the end of the observation (by 9-10 days of life, thromboxane B2 was $104.0 \pm 0.09 \mathrm{pc} / \mathrm{ml}, \quad 6$-keto-prostaglandin $\mathrm{F} 1 \alpha$ $74.5 \pm 0.13 \mathrm{pc} / \mathrm{ml})$.

Table 1. Condition of hematological parameters in the examined calves

\begin{tabular}{|l|c|c|c|c|c|}
\hline \multicolumn{1}{|c|}{$\begin{array}{l}\text { Registrated } \\
\text { parameters }\end{array}$} & \multicolumn{4}{c|}{ Calf age, $\mathrm{n}=32, \mathrm{M} \pm \mathrm{m}$} \\
\cline { 2 - 6 } & 1-2 day of life & $\begin{array}{c}3-4 \text { day of } \\
\text { life }\end{array}$ & $\begin{array}{c}5-6 \text { day of } \\
\text { life }\end{array}$ & $\begin{array}{c}7-8 \text { day of } \\
\text { life }\end{array}$ & $\begin{array}{c}\text { 9-10 day of } \\
\text { life }\end{array}$ \\
\hline Thromboxane $\mathrm{B}_{2, \mathrm{pg} / \mathrm{ml}}$ & $102.1 \pm 0.05$ & $102.9 \pm 0.12$ & $103.1 \pm 0.10$ & $103.6 \pm 0.07$ & $104.0 \pm 0.09$ \\
\hline 6-keto-prostaglandin $\mathrm{F}_{1 \alpha}, \mathrm{pg} / \mathrm{ml}$ & $72.3 \pm 0.10$ & $73.0 \pm 0.12$ & $73.4 \pm 0.08$ & $73.9 \pm 0.07$ & $74.5 \pm 0.13$ \\
\hline $\begin{array}{l}\text { The sum of all red blood cells in the } \\
\text { aggregate }\end{array}$ & $38.5 \pm 0.24$ & $39.2 \pm 0.31$ & $39.6 \pm 0.39$ & $39.9 \pm 0.27$ & $40.3 \pm 0.38$ \\
\hline The number of erythrocyte aggregates & $8.0 \pm 0.14$ & $8.0 \pm 0.18$ & $8.1 \pm 0.09$ & $8.1 \pm 0.15$ & $8.2 \pm 0.19$ \\
\hline The number of free red blood cells & $253.1 \pm 1.34$ & $251.0 \pm 1.63$ & $250.1 \pm 1.42$ & $248.9 \pm 2.08$ & $247.2 \pm 1.85$ \\
\hline Aggregation platelet with ADP, s & $40.8 \pm 0.14$ & $40.6 \pm 0.16$ & $40.3 \pm 0.10$ & $40.0 \pm 0.18$ & $39.8 \pm 0.19$ \\
\hline Aggregation platelet with collagen, s & $31.6 \pm 0.19$ & $31.4 \pm 0.12$ & $31.3 \pm 0.11$ & $31.0 \pm 0.09$ & $30.8 \pm 0.17$ \\
\hline Aggregation platelet with thrombin, $\mathrm{s}$ & $53.9 \pm 0.14$ & $53.6 \pm 0.12$ & $53.2 \pm 0.19$ & $52.8 \pm 0.14$ & $52.6 \pm 0.20$ \\
\hline Aggregation platelet with ristomycin, $\mathrm{s}$ & $48.6 \pm 0.14$ & $48.5 \pm 0.19$ & $48.2 \pm 0.21$ & $47.8 \pm 0.19$ & $47.5 \pm 0.23$ \\
\hline Aggregation platelet with adrenaline, $\mathrm{s}$ & $99.8 \pm 0.34$ & $99.3 \pm 0.29$ & $98.9 \pm 0.37$ & $98.4 \pm 0.28$ & $97.9 \pm 0.31$ \\
\hline Aggregation of neutrophils with lectin, \% & $14.2 \pm 0.12$ & $14.2 \pm 0.18$ & $14.3 \pm 0.16$ & $14.4 \pm 0.23$ & $14.6 \pm 0.20$ \\
\hline $\begin{array}{l}\text { Aggregation of neutrophils with concanavalin } \\
\text { A, \% }\end{array}$ & $13.5 \pm 0.13$ & $13.7 \pm 0.14$ & $13.9 \pm 0.18$ & $14.2 \pm 0.09$ & $14.5 \pm 0.15$ \\
\hline $\begin{array}{l}\text { Aggregation of neutrophils with } \\
\text { phytohemagglutinin, \% }\end{array}$ & $26.2 \pm 0.16$ & $26.5 \pm 0.18$ & $26.7 \pm 0.16$ & $26.9 \pm 0.15$ & $27.2 \pm 0.22$ \\
\hline
\end{tabular}

Note: the reliability of the dynamics of the indicators taken is not received.

During the observation period in calves was found a tendency to increase spontaneous aggregation of erythrocytes, as indicated by the tendency to increase the total number of erythrocytes in the unit $(4.7 \%)$, the increase in the quantity of erythrocyte aggregates $(2.5 \%)$ and slight downward trend in the number of available red blood cells $(2.4 \%)$ (table 1$)$.

All calves during the observation period found a trend to increased platelet aggregation in response to all tested inducers (table 1).

During the phase from the observed neonatal calves revealed a tendency to increase aggregation of neutrophils (table 1) in relation to lectin, concanavalin A and phytohemagglutinin (table 1).

\section{Discussion}

Cattle are currently an important source of milk and meat. For this reason, a detailed study of its physiology has been conducted for a long time in order to clarify its biological potential [15]. As a result of systematic research, it was possible to collect a large amount of data on various aspects of the age-related physiology of this species of productive animals. However, the information available cannot be considered complete. There remains a great need for new knowledge and clarification of the collected information on the functioning of the body systems of this species of productive animals at different ages. Closing the gaps in existing physiological knowledge should help in the development of effective 
approaches to ensure functional optimum in cattle throughout ontogenesis, which will ensure maximum productivity [16].

The normal course of ontogenesis of the organism of productive animals is always ensured by the continuous adaptation of the mechanisms of maintaining homeostasis in it to the action of any environmental factors. Fully based on the genetic program, all biological processes in the ontogenesis of cattle experience age-related dynamics, allowing animals to adapt to living conditions that can, at times, disrupt the functioning of the body.

Of great importance in maintaining homeostasis is blood and its mechanisms of rheology and hemostasis, which largely limit the level of perfusion of animal tissues, and, therefore, the course of many life processes in them. Gradually, there comes an understanding that the ontogenetic dynamics of the rheological parameters of blood, which largely depend on the aggregation of blood cells, should be considered as an important component of the regulation of anabolism in animal tissues [17].

In this regard, research on the physiology of blood in newborn calves, which have begun their independent existence outside the maternal organism, is very important. In the work performed, the observed calves have noted regular changes in the hematological parameters taken into account. The revealed facts were confirmed by the results of earlier studies. It is known that the intensity of thromboxane formation and the level of thromboxane in plasma has a significant effect on the ability to aggregate red blood cells, platelets, and white blood cells.

So, during the neonatal period in calves, a slight tendency was found to increase the formation of thromboxane $\mathrm{A}_{2}$ and enhance the synthesis of prostacyclin [18]. This can explain the changes observed in the observed calves at the beginning of their ontogenesis of the severity of aggregation of their basic blood cells.

During the neonatal period, calves showed a tendency towards an increase in red blood cell aggregation. Obviously, the aggregation of red blood cells in calves is strongly ensured by the optimal electronegativity of their surfaces due to the sufficient number of proteins with a negative charge on it [19].

The effectiveness of control over the formation of reactive oxygen species creates a minimum of oxidative alteration of these proteins in membranes and capable of participating in the aggregation of plasma proteins [20]. Interacting on the surface of red blood cells with receptors, they maintain the optimum activity of adenylate cyclase and phosphodiesterase, maintaining the physiological balance of the amounts of cyclic AMP and $\mathrm{Ca}^{2+}$ in them [21].

In this regard, there is a reason to believe that the neonatal phase in calves is characterized by the optimum of metabolic and receptor processes in red blood cells. At the same time, a low aggregation of erythrocytes and a high number of free red blood cells recorded in calves at this age provide an optimum perfusion of their internal organs.
The high degree of vascular control over calf erythrocyte aggregation at the beginning of ontogenesis during the course of the observation, obviously, lays the foundation for intensive microcirculation of high supply of animal tissues with oxygen and nutrients.

During the first days of life, calves showed a weak tendency to increase platelet aggregation activity. The calf hemostatic properties of their platelets observed in calves are largely due to the stability of their receptors and the sufficiently functional capabilities of the postreceptor aggregation mechanisms.

In addition, in the blood of calves at the age of the first 10 days, there was a low concentration of von Willebrand factor, which is a cofactor of platelet adhesion with a sufficient number of receptors for it (GPIв) on the surface of these blood cells. This was indicated by a slight tendency to reduce the time of AP in newborn calves in response to ristomycin. The found state of AP dynamics in response to strong and weak aggregation agonists can be explained by physiologically justified fluctuations in the activity of platelet phospholipases $A_{2}$ and $C$, which ensure the functioning of the thromboxane and phosphoinositol platelet activation pathways [22].

In addition, the found tendency to accelerate AP in calves of the first 10 days of life was probably a consequence of the tendency to increase the production of thromboxane in platelets and an increase in the density of receptors for it on the platelet surface. The low AP in calves in response to all inducers was associated with the physiologically minimal activity of platelet proteins - carriers of the stimulating signal from receptors into platelets [23, 24].

The low aggregation of neutrophils found in calves was associated with the optimum of their aggregation capabilities and the normal composition of glycoprotein receptors on neutrophil membranes that can bind to lectins. The found tendency to an increase in lectin- and concanavalin A-induced neutrophil aggregation in calves was ensured by a tendency to increase the expression of these receptors with an increase in their composition of loci with $\mathrm{N}$-acetyl-D-glucosamine, $\mathrm{N}$-acetyl-neuraminic acid and mannose [25].

The revealed tendency towards an increase in the aggregation of neutrophils with phytohemagglutinin was caused by a tendency to increase bD galactose in their receptors. Also, the low aggregation ability of neutrophils can be associated with their high sensitivity to vascular disaggregation influences, apparently due to the powerful production of prostacyclin and NO in the vessels of newborn animals $[17,26]$.

\section{Conclusion}

Now it becomes clear that the aggregation capabilities of blood cells to a large extent determine the rheology of blood, and, therefore, the optimum microcirculation in animal tissues throughout ontogenesis. This is very significant for the growth processes and the maximum development of the productive properties of animals. In newborn calves of optimal physiological status, there is a 
slight tendency to increase aggregation of red blood cells, platelets and neutrophils. The observed optimum aggregation activity of erythrocytes, platelets and neutrophils in calves during the neonatal phase is extremely necessary to maintain their homeostasis and create conditions for further growth and development. The rapid inclusion of adaptive mechanisms under these conditions maintains the balance of aggregation and disaggregation in the blood of calves at the level required for optimal perfusion of internal organs and metabolism in tissues. The presence of a low severity of the aggregation properties of blood cells is obviously the basis for the successful progress of the adaptation process throughout the body in calves during the newborn and the creation of the basis for their successful transition to the next stage of early ontogenesis.

\section{References}

1. H. Kulig, K. Żukowski, I. Kowalewska-Łuczak, P. Łakomy, ScdlPolymorphism and Breeding Value for Milk Production Traits in Cows, Bulgar. J. of Agricult. Sci., 22, 131-134 (2016)

2. E.S. Tkacheva, S.Yu. Zavalishina, Physiological Aspects Of Platelet Aggregation In Piglets Of Milk Nutrition, Res. J. of Pharmaceut., Biolog. and Chemical Sci., 9(5), 74-80 (2018)

3. G.N. Sushkevich, Abnormal hemostasis system and the principles of their correction (Sovetskaya Kuban, Krasnodar, 2010)

4. S.Yu. Zavalishina, Deficiency Of Iron As A Cause Of Dysfunction In Calves And Piglets, Res. J. of Pharmaceut., Biolog. and Chemical Sci., 9(5), 978983 (2018)

5. Gunay Aytekin, Ulgen Gunay, Abdülkadir Orman, Effects of retained placenta on the fertility in treated dairy cows, Bulgar. J. of Agricult. Sci., 17, 126-131 (2011)

6. S.Yu. Zavalishina, Functional Activity of Anticoagulant System In Calves During Early Ontogeny, Res. J. of Pharmaceut., Biolog. and Chemical Sci., 9(5), 837-843 (2018)

7. L. Burnier, P. Fontana, B.R. Kwak, A. AngelilloScherrer, Cell-derived microparticles in haemostasis and vascular medicine, Thromb. Haemost, 101, 439-451 (2009)

8. S.Yu. Zavalishina, Functional Properties Of Fibrinolysis In Calves Of The First Year Of Life, Res. J. of Pharmaceut., Biolog. and Chemical Sci., 9(5), 870-876 (2018)

9. A.A. Bikbulatova, Creating Psychological Comfort In Women Who Wear Corrective Clothing For A Long Time, Res. J. of Pharmaceut., Biolog. and Chemical Sci., 9(6), 1112-1121 (2018)

10. S.Yu. Zavalishina, Functional Properties Of Coagulation Hemostasis In Calves During The Phase Of Dairy-Vegetative Nutrition, Res. J. of Pharmaceut., Biolog. and Chemical Sci., 9(5), 784-790 (2018)
11. G.C. White, R. Rompietti, Platelet secretion: indiscriminately spewed forth or highly orchestrated? J. Thromb. Haemost, 5, 2009-2016 (2007)

12. S.Yu. Zavalishina, Functioning Of Mechanisms Of Hemocoagulation Restriction In Calves At Change Of Methods Of Nutrition, Res. J. of Pharmaceut., Biolog. and Chemical Sci., 9(5), 800-806 (2018)

13. E.S. Tkacheva, S.Yu. Zavalishina, Physiology of Platelet Hemostasis In Piglets During The Phase Of Newborns, Res. J. of Pharmaceut., Biolog. and Chemical Sci., 9(5), 1912-1918 (2018)

14. S.Yu. Zavalishina, Functional Properties Of Anticoagulation And Fibrinolysis In Calves Of Plant Nutrition, Res. J. of Pharmaceut., Biolog. and Chemical Sci., 9(5), 1082-1087 (2018)

15. C. Tóthová, O. Nagy, G. Kováč, V. Nagyová, Changes in the concentrations of serum proteins in calves during the first month of life, J. of Applied Animal Res., 44(1), 338-346 (2016)

16. A.A. Bikbulatova, Functional Features Of Microcirculatory Processes In Obese Women Against A Background Of Long Daily Wearing Of Corrective Clothing, Res. J. of Pharmaceutical, Biolog. and Chemical Sci., 9(6), 785-793 (2018)

17. S.Yu. Zavalishina, Physiology of Vascular Hemostasis In Newborn Calves, Res. J. of Pharmaceut., Biolog. and Chemical Sci., 9(5), 1037-1044 (2018)

18. A.S. Shitikova, Thrombocytopathy congenital and acquired (St. Petersburg, 2008)

19. S.Yu. Zavalishina, Functional Properties Of Hemocoagulation In Calves Of Dairy Nutrition, Res. J. of Pharmaceut., Biolog. and Chemical Sci., 9(5), 1016-1022 (2018)

20. S.Yu. Zavalishina, Physiological Features of Vascular Hemostasis In Calves Of Dairy-Vegetative Food, Res. J. of Pharmaceut., Biolog. and Chemical Sci., 9(5), 1137-1143 (2018)

21. L.V. Korepanova, O.S. Starostina, S.D. Batanov, Blood as an indicator of the interior characteristics of crossbred animals, Zootechny, 10, 26-28 (2015)

22. S.Yu. Zavalishina, Functional Antiaggregatory Properties Of Blood Vessels In Calves During Transition From Dairy To Plant Type Of Nutrition, Res. J. of Pharmaceut., Biolog. and Chemical Sci., 9(5), 1110-1116 (2018)

23. B.V. Usha, S.Y. Zavalishina, Y.A. Vatnikov, E.V. Kulikov, V.I. Kuznetsov, N.V. Sturov, M.V. Kochneva, A.A. Poddubsky, A.V. Petryaeva, T.I. Glagoleva, Diagnostics of early dysfunctions of anticoagulant and fibrinolytic features of rats' vessels in the course of metabolic syndrome formation with the help of fructose model, Bali Med. J., 8(1), 201-205 (2019)

24. N.V. Vorobyeva, G.S. Mal, S.Yu. Zavalishina, T.I. Glagoleva, I.I. Fayzullina, Influence Of Physical Exercise On The Activity Of Brain Processes, Res. J. of Pharmaceut., Biolog. and Chemical Sci., 9(6), 240-244 (2018)

25. Yu. Vatnikov, A. Rudenko, P. Rudenko, Ev. Kulikov, A. Karamyan, V. Lutsay, I. Medvedev, V. Byakhova, E. Krotova, M. Molvhanova, Immune- 
inflammatory concept of the pathogenesis of chronic heart failure in dogs with dilated cardiomyopathy, Veterinary World, 12(9), 1491-1498 (2019)
26. I.N. Medvedev, Physiological peculiarities of thrombocyte activity of candidates into masters of sports in athletics of preadult age, Bali Medical J., 8(3), 635-639 (2019) 